\title{
Use of nasal preparations and the incidence of sinonasal cancer
}

\author{
CLIFTON H STRADER, ${ }^{1}$ THOMAS L VAUGHAN, ${ }^{2}$ AND ANDY STERGACHIS 4 \\ From the Hanford Environmental Health Foundation,' Post Office Box 100, Richland, Washington 99352; the \\ Division of Public Health Sciences, Fred Hutchinson Cancer Research Center, ${ }^{2} 1124$ Columbia Street (W-404), \\ Seattle, Washington 98195; the Department of Epidemiology, School of Public Health and Community Medicine, ${ }^{3}$ \\ University of Washington, Seattle, Washington 98195; and the Group Health Cooperative of Puget Sound, Inc., ${ }^{4}$ \\ Center for Health Studies, 200-15th Avenue East, Seattle, Washington 98112.
}

SUMMARY Data from a population based case control study in western Washington were analysed to determine whether the use of nasal sprays and drops was associated with an increased risk of sinonasal cancer. Telephone interviews were conducted with incident cases $(n=53)$ diagnosed between 1979 and 1983 or their next-of-kin, and with controls $(n=552)$ regarding their past use of nasal preparations, history of rhinologic problems, smoking history, alcohol consumption, and a number of other known or suspected risk factors. Both cigarette smoking and alcohol consumption were associated with an increased risk of sinonasal cancer; the strongest associations were found with squamous cell tumours. Subjects who reported a history of nasal preparation use were 3.5 times $(95 \%$ confidence interval $=1 \cdot 7-7 \cdot 0$ ) more likely than non-users to develop sinonasal cancer. The risk of sinonasal cancer increased with increasing duration of use of nasal preparations. These findings suggest the need for a more detailed investigation of the possible adverse consequences of long-term use of nasal preparations.

Nasal sprays and drops have been in use since the early 1900 s to alleviate the symptoms of allergic rhinitis, upper respiratory tract infections, and nasal polyps. The most common of these preparations, widely available as non-prescription drugs, are decongestants containing one or more sympathomimetic compounds. Corticosteroid nasal sprays, available only by prescription, are a second group of compounds which are used in the treatment of nasal polyps and allergic rhinitis.

The potential health consequences of chronic use of these nasal preparations are not fully known. Common adverse reactions to corticosteroid preparations include irritation and dryness of the nasal mucosa, although perforation of the nasal septum has also been noted. ${ }^{12}$ Toohill $e t a l^{3}$ have suggested that the long-term use of topical decongestants may be related to the development of nasal polyposis and ethmoiditis. More recently, Hayes et $a l^{4}$ reported a five-fold excess risk of sinonasal cancer among men with a history of nasal spray use, although no excess risk was found among women with such a history.

As part of a case-control study designed to investigate formaldehyde as a potential risk factor for pharyngeal and sinonasal cancer, ${ }^{5}$ we assessed the history of nasal preparation use and rhinologic conditions among respondents. This report presents results concerning the use of nasal preparations as a risk factor for sinonasal cancer.

\section{Methods}

Cases were identified by the Cancer Surveillance System of the Fred Hutchinson Cancer Research Center, a population-based cancer registry operated as part of the Surveillance, Epidemiology and End Results programme of the National Cancer Institute. The registry identifies $98-99 \%$ of all incident cancer cases occurring among residents of 13 counties of western Washington. Patients who were eligible for participation in the study were all cases of sinonasal cancer (ICD- $0^{6}$ sites 160.0-160.9) who were (a) diagnosed between January 1979 and December 1983, (b) residents of western Washington when diagnosed,

(c) between 20 and 74 years of age at diagnosis, and (d) lived in a residence that had a telephone. Seventy-eight eligible sinonasal cancer cases were identified.

Attempts were made during 1983-85 to conduct interviews by telephone with live patients or the 
next-of-kin of deceased patients. Subjects no longer residing in western Washington for whom a telephone number could be found were also contacted for interview. Interviews were completed with $56(71.8 \%)$ of the 78 eligible sinonasal cancer patients and next-ofkin. Since cases diagnosed as early as 1979 were included in the study and interviewing did not begin until late in 1983, approximately $40 \%$ of the 56 cases were deceased before an interview could be arranged.

Physicians refused permission to contact four $(5 \cdot 1 \%)$ patients and next-of-kin and five (6.4\%) patients and next-of-kin declined to participate. Thirteen $(16.7 \%)$ of the cases were considered lost to follow-up either because they left the area and could not be found or because no next-of-kin could be identified. Three of the 56 interviewed cases were later excluded due to ineligible cancer site. Thirty-two of the remaining interviews were conducted with sinonasal cancer patients and 21 interviews were conducted with next-of-kin. Compared with respondents, nonrespondents were more likely to be deceased at ascertainment and to have squamous cell tumours. The two groups were similar with regard to age, race and sex. No cases were lost due to lack of a telephone.

Controls were selected by the method of random digit dialling. ${ }^{7}$ Telephone numbers were randomly generated from a list of working exchanges for the 13 counties. Each number was called up to nine times at different times of the day and week to determine if the number were residential and, if so, whether or not the household contained an eligible resident. Controls were selected to be similar to cases with respect to age and sex. When more than one eligible control resided in a household, only one was randomly selected to be interviewed.

We were able to determine the county of residence and number of men and women in the age group of interest for $95.8 \%$ of the households contacted. Telephone interviews were completed for $573(83.0 \%)$ of the 690 eligible controls, yielding an overall response for both screening and interviewing of $79.5 \%$. Twenty-one controls were later excluded on the basis of ineligible age, as determined at the time of interview.

The telephone interview included questions regarding demographic characteristics such as educational attainment and race, the number of weeks per year and number of years during which nasal preparations were used, medical history of nasal and throat conditions, a lifetime smoking history, and usual alcohol consumption in the recent past. Exposure history was determined for the period greater than 1 year prior to interview for controls or greater than 1 year prior to diagnosis for cases.
STATISTICAL ANALYSES

Estimates of the relative risk associated with nasal preparations were derived from calculation of the exposure odds ratio. Stratified analysis was used to assess the importance of the potential confounding factors and to adjust the risk estimates for their effect. ${ }^{8}$ Cornfield's method ${ }^{9}$ was used to calculate $95 \%$ confidence intervals $(\mathrm{CI})$. Fisher's exact test ${ }^{10}$ was used to calculate confidence intervals when small cell sizes made estimation by asymptotic methods inappropriate. Additional analyses of the relationship between smoking, alcohol consumption, and sinonasal cancer were performed using a conditional multiple logistic regression model. ${ }^{11}$

\section{Results}

Selected clinical and demographic characteristics of the sinonasal cancer cases and controls are shown in table 1. Twenty-seven of the sinonasal cancer cases had squamous cell tumours. Twenty other cases were classified histologically as having mesenchymal tumours $(n=6)$, adenocarcinoma $(n=6)$, lymphoma $(n=6)$, or melanoma $(n=2)$. Six cases were histologically unspecified. As a group, sinonasal cancer cases were slightly older than the controls but were similar to controls with respect to sex and racial distributions. Fewer sinonasal cancer cases than controls had received some college or technical education.

Table 1 Selected clinical and demographic characteristics of sinonasal cancer cases and controls

\begin{tabular}{|c|c|c|c|c|}
\hline \multirow[b]{2}{*}{ Total } & \multicolumn{2}{|c|}{$\begin{array}{l}\text { Cases } \\
n(\%)\end{array}$} & \multicolumn{2}{|c|}{$\begin{array}{l}\text { Controls } \\
n(\%)\end{array}$} \\
\hline & 53 & $(100 \cdot 0)$ & 552 & $(100 \cdot 0)$ \\
\hline \multicolumn{5}{|l|}{ Histology } \\
\hline Squamous & 27 & $(50 \cdot 9)$ & - & \\
\hline Adenocarcinoma & 6 & $(11 \cdot 3)$ & - & \\
\hline Mesenchymal & 6 & $(11 \cdot 3)$ & - & \\
\hline Lymphoma & 6 & $(11 \cdot 3)$ & - & \\
\hline Melanoma & 2 & $(3 \cdot 8)$ & - & \\
\hline Unspecified & 6 & $(11 \cdot 3)$ & - & \\
\hline \multicolumn{5}{|l|}{ Age } \\
\hline $20-49$ & 9 & $(17 \cdot 0)$ & 109 & $(19 \cdot 7)$ \\
\hline $50-59$ & 15 & $(28 \cdot 3)$ & 165 & $(29.9)$ \\
\hline $60-74$ & 29 & $(54 \cdot 7)$ & 278 & $(50 \cdot 4)$ \\
\hline \multicolumn{5}{|l|}{ Sex } \\
\hline Male & 33 & $(62 \cdot 3)$ & 327 & $(59 \cdot 2)$ \\
\hline Female & 20 & $(37 \cdot 7)$ & 225 & $(40 \cdot 8)$ \\
\hline \multicolumn{5}{|l|}{ Education } \\
\hline Elementary & 6 & $(11 \cdot 3)$ & 26 & $(4 \cdot 7)$ \\
\hline High School & 23 & $(43.4)$ & 246 & $(44 \cdot 6)$ \\
\hline College & 21 & $(39 \cdot 6)$ & 241 & $(43 \cdot 7)$ \\
\hline Technical & 3 & $(5 \cdot 7)$ & 39 & $(7 \cdot 1)$ \\
\hline \multicolumn{5}{|l|}{ Race } \\
\hline White & .51 & $(96 \cdot 2)$ & 526 & $(95 \cdot 3)$ \\
\hline Black & 0 & $(0.0)$ & 11 & $(2 \cdot 0)$ \\
\hline Other & 2 & $(3 \cdot 8)$ & 15 & $(2 \cdot 7)$ \\
\hline
\end{tabular}


Compared with respondents who had smoked cigarettes for one pack-year or less, those who had smoked $\mathbf{4 0}$ or more pack-years had a relative risk of $1.7(95 \% \mathrm{CI}=0.8-3.9)$. The relative risk (RR) of sinonasal cancer increased with increasing levels of cigarette smoking. Similarly, an increasing relative risk was observed with increasing frequency of alcohol consumption, with an approximately three-fold relative risk $(R R=3.4 ; 95 \% C I=1.4-8.4)$ observed among subjects who reported consumption of 21 or more drinks per week. Cigarette smoking and alcohol consumption were most closely associated with squamous cell tumours; the risk of squamous cell cancer associated with smoking 40 or more pack-years was $6.6(95 \% \mathrm{CI}=1 \cdot 7-29.6)$ and a relative risk of 6.8 (95\% CI $=2 \cdot 1-22 \cdot 0)$ was observed among subjects who reported alcohol consumption of 21 or more drinks per week.

To control for the joint confounding effects of smoking and alcohol use and to examine interaction between these two factors, a conditional logistic model matching on age (5 year age groups) and sex was employed. The model contained cigarette use grouped into categories of $0-1,2-19,20-39,40-59$, and $60+$ pack-years and entered as a continuous variable with values equal to the category medians, and recent alcohol consumption grouped into categories of $0-6$, $7-20$, and $21+$ drinks per week and entered as a continuous variable using median levels. Table 2 represents the relative risk of squamous cell sinonasal cancer associated with selected levels of cigarette and alcohol use. There was no evidence of interaction between alcohol and smoking when the multiplicative model was used.

Table 2 Relative risk of squamous cell sinonasal cancer associated with cigarette and alcohol use*

\begin{tabular}{lllll}
\hline & & \multicolumn{3}{c}{ Cigarettes (pack-years) } \\
\cline { 3 - 5 } & & 0 & 20 & 40 \\
\hline Alcohol & 0 & 1.0 & 1.5 & 2.2 \\
(Drinks & 10 & 1.5 & 2.3 & 3.4 \\
per week) & 20 & 2.4 & 3.5 & 5.3 \\
\hline
\end{tabular}

\footnotetext{
Regression coefficients:

Alcohol: $0.0430(p=0.004)$

Cigarettes: $0.0202(p=0.005)$
}

We found a strong association between a history of nasal preparation use and an increased risk of sinonasal cancer $(R R=3.5 ; 95 \% C I=1 \cdot 7-7 \cdot 0$; table $3)$. This association was not present in our concurrent study of risk factors for pharyngeal cancer. Sinonasal cancer was not closely associated with a history of nasal polyps $(R R=1 \cdot 7 ; 95 \% C I=0.4-6.3)$, hayfever $(R R=1.2 ; 95 \% \quad C I=0.5-2.7)$, or other ear-nosethroat problems such as deviated septum and
Table 3 Distribution of selected risk factors among sinonasal cancer cases and controls

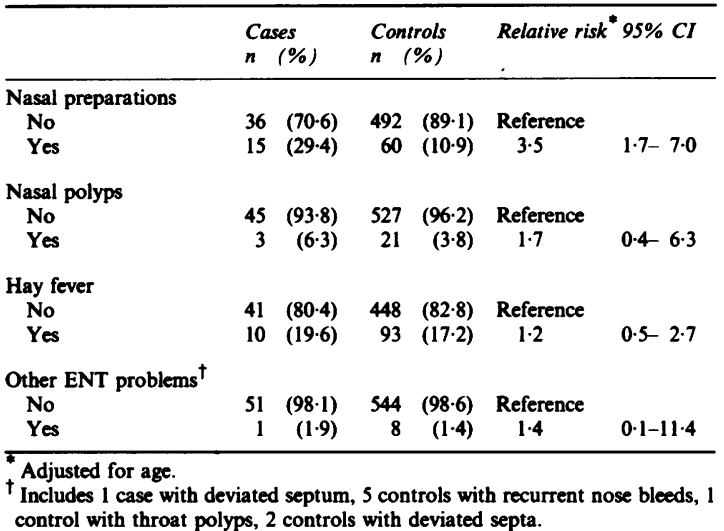

recurrent nosebleeds $(R R=1 \cdot 4 ; 95 \% C I=0 \cdot 1-11 \cdot 4)$. The relative risk associated with the use of nasal preparations did not vary appreciably with adjustment for sex, alcohol consumption, smoking, wood dust exposure, or the sinonasal conditions mentioned above.

The use of nasal preparations was strongly associated with cancer of the nasal sinuses $(R R=5 \cdot 2$; 95\% CI = 1.9-13.4) (ICD-0 site codes 160.2-160.7; $\mathrm{n}=23$ cases $)$. We found a relative risk of $1.7(95 \%$ $\mathrm{CI}=0.5-5.5$ ) for tumours of the nasal cavity (ICD-0 site code $160.0, n=24$ cases), and $7.9(95 \% \mathrm{CI}=0.8-$ 84.7) for tumours of other sinonasal sites (ICD- 0 site codes 160.1 and $160.8, n=4$ cases). An examination of the variation in relative risk by histologic type revealed the strongest association with adenocarcinoma $(\mathrm{RR}=8.0 ; 95 \% \mathrm{CI}=1 \cdot 2-50 \cdot 2)$; the relative risks were smaller for squamous cell $(\mathrm{RR}=3.6,95 \% \mathrm{CI}=1.4$ 9.4) and other histologic types ( $R R=2.3,95 \%$ $\mathrm{CI}=0 \cdot 6-7 \cdot 7)$.

To investigate whether the risk of sinonasal cancer increased with increasing use of nasal preparations, we examined both the frequency (weeks per year) and duration (number of years) of nasal preparation use. The risk of sinonasal cancer increased with increasing weeks per year of use and increasing years of use. Compared with respondents who reported using nasal preparations less than one week per year, those who reported 26 or more weeks per year of use had a relative risk of $3 \cdot 8$. A six-fold increase in relative risk was observed for respondents who reported ten or more years of use compared with those who had used nasal preparations 1 year or less. Since nasal preparations may be used to relieve symptoms brought on by a number of medical conditions which may be risk factors for sinonasal cancer, we repeated this analysis excluding nine cases and 32 controls with a history of nasal polyps or other ear-nose-throat 
problems (one case with deviated septum, five controls with recurrent nosebleeds, one control with throat polyps, two controls with deviated septa). The exclusion of these subjects had little impact on the magnitude of the observed risks.

An examination of total weeks of nasal preparation use (frequency $\times$ duration) revealed an almost ninefold increase in risk for subjects who had 520 or more total weeks of use. The magnitude of this risk reflects the close association between frequency and duration of use; subjects who reported using nasal preparations for many years also tended to use them for many weeks per year. When next-of-kin interviews were excluded from analysis, the RR associated with 520 or more total weeks of use was $7 \cdot 0$ (table 4).

Table 4 Total weeks of nasal preparation use among cases and controls*

\begin{tabular}{|c|c|c|c|c|c|c|}
\hline All cases & \multicolumn{2}{|c|}{$\begin{array}{l}\text { Cases } \\
n \quad(\%)\end{array}$} & \multicolumn{2}{|c|}{$\begin{array}{l}\text { Controls } \\
n \quad(\%)\end{array}$} & $\begin{array}{l}\text { Relqtive } \\
\text { risk }\end{array}$ & $\begin{array}{l}95 \% \text { Confidence } \\
\text { interval }\end{array}$ \\
\hline $\begin{array}{l}\text { All cases } \\
\leq 52 \\
53-519 \\
\geq 520\end{array}$ & $\begin{array}{r}41 \\
2 \\
5\end{array}$ & $\begin{array}{r}(85 \cdot 4) \\
(4 \cdot 2) \\
(10 \cdot 4)\end{array}$ & $\begin{array}{r}524 \\
19 \\
7\end{array}$ & $\begin{array}{r}(95 \cdot 3) \\
(3 \cdot 5) \\
(1 \cdot 3)\end{array}$ & $\begin{array}{c}\text { Reference } \\
1.4 \\
8.7\end{array}$ & $\begin{array}{l}0.2-6.5 \\
2.4-33.8\end{array}$ \\
\hline $\begin{array}{l}\text { Excluding ne } \\
\leq 52 \\
53-519 \\
\geq 520\end{array}$ & $\begin{array}{r}\text { f-kin } \\
29 \\
0 \\
3\end{array}$ & $\begin{array}{r}\text { intervie } \\
(90 \cdot 6) \\
(0.0) \\
(9 \cdot 4)\end{array}$ & $\begin{array}{r}\text { 1s } \\
524 \\
19 \\
7\end{array}$ & $\begin{array}{r}(95 \cdot 3) \\
(3 \cdot 5) \\
(1 \cdot 3)\end{array}$ & $\begin{array}{c}\text { Reference } \\
0 \\
7.0\end{array}$ & $\begin{array}{c}0-4 \cdot 1 \neq \\
1 \cdot 4-34.5\end{array}$ \\
\hline
\end{tabular}

Excludes 5 cases and 2 controls for whom total weeks of use could not be calculated

$\ddagger$ Adjusted for age.
Confidence interval calculated by Fisher's Exact Test. 10

\section{Discussion}

Some aspects of this study require that caution be used in the interpretation of the results. We interviewed 32 sinonasal cancer cases, 18 next-of-kin of deceased cases, and three next-of-kin of living cases who were unable to participate. By contrast, all control interviews were conducted with living controls. To the extent that recall of nasal preparation use differed between cases and controls and between living cases and next-of-kin, the results we obtained may be biased. However, the exclusion of next-of-kin respondents from the analysis had little impact on the risk associated with 520 or more weeks of nasal preparation use (table 4), suggesting that the association cannot be attributed to this potential source of bias.

An additional limitation of the study is that a history of nasal preparation use was determined only by telephone interview. Because sympathomimetic nasal preparations are available over the counter, validation of self-reported use of these preparations is difficult. In an attempt to validate the response of subjects regarding the regular long-term use of nasal preparations, one of us (AS) examined computerised pharmacy records maintained by one of the participating health maintenance organisations. Pharmacy records of this organisation include virtually all prescription medications used by members since 1977. Members may also obtain overthe-counter preparations by prescription at no cost; these medications are also entered into the records. Of the six interviewed sinonasal cancer cases who were members of this health maintenance organisation, one had reported the regular use of nasal preparations. This patient's pharmacy record revealed that seven individual prescriptions for nasal preparations had been filled one year or more before the date of diagnosis. Six of the seven prescriptions involved a corticosteroid compound. Of the five sinonasal cancer cases who reported no history of regular nasal preparation use, two had a record of only one prescription for a sympathomimetic compound. Thus this attempt to verify exposure histories was limited to an examination of regular versus occasional use as reflected in these cases' medical records, and could not address over-the-counter purchases which were not made at the health maintenance organisation. The anonymity of controls precluded a similar investigation of their pharmacy records. In summary, the reported long-term use of preparations by one of the six sinonasal cancer cases was supported by the presence of multiple prescriptions on pharmacy records while all five negative histories were supported in the sense that multiple prescriptions were not found (although two cases who did not report regular use of nasal preparations did each have a record of one prescription for a sympathomimetic compound).

Although the interviews included questions regarding the number of weeks per year and total number of years of nasal preparation use, we did not ask for information regarding the specific type of preparation or whether the drug was obtained by prescription or over the counter. Thus our analysis made no distinction between preparations containing sympathomimetic agents and those containing corticosteroids.

An association between smoking and sinonasal cancer has been previously reported. ${ }^{12-14}$ Hayes et al $^{13}$ noted a moderate increase in risk associated with smoking but did not report the impact of smoking on specific histologic types of tumours. Elwood ${ }^{14}$ observed an excess risk for all histologic types of sinonasal cancer, finding the strongest associations with transitional cell and squamous cell tumours. Brinton et $a l^{12}$ also found that smoking was most closely associated with an increased risk of squamous cell carcinoma.

Our finding of an association between alcohol consumption and squamous cell sinonasal cancer has 
not been reported by other investigators. ${ }^{12} 13$ Brinton et $a^{12}$ observed little impact of alcohol use on the risk of any histologic type of sinonasal cancer, nor did alcohol modify the association of these cancers with smoking in an important way. The association with alcohol observed in our study is unlikely to have arisen from differences in the reporting of alcohol use by live cases and next-of-kin; the increased risk was observed in both groups. Under-reporting of alcohol consumption by controls could account for at least part of the observed association.

An association between the use of nasal preparations and an increased risk of sinonasal cancer was previously reported by Hayes et $\mathrm{al}^{4}{ }^{4}$ who found a five-fold increased risk among men with a history of nasal spray use but no increase in risk among women with this exposure. By contrast, Brinton et al ${ }^{12}$ found no association between regular use of nose drops and sinonasal cancer risk after controlling for a history of sinus trouble. We found an increased risk of sinonasal cancer among both men $(R R=2 \cdot 8)$ and women $(\mathrm{RR}=4 \cdot 9)$.

Any rhinologic condition which produces nasal congestion or occludes the nasal passages must be considered as a potential reason for the use of topical decongestants. Toohill $e t \mathrm{al}^{3}$ found that among 130 patients diagnosed as having rhinitis medicamentosa, $43(33 \%)$ had initiated the use of topical decongestants to relieve nasal congestion produced by deviation of the nasal septum. An additional $33(25 \%)$ patients began the self-medication to relieve congestion associated with upper respiratory tract infections. It is possible that such underlying conditions might in themselves increase the risk of sinonasal cancer. Brinton et al ${ }^{12}$ reported an increased risk of sinonasal cancer associated with a history of sinus trouble, nasal polyps and recurrent nose-bleeds. However, we found only a weak association between a history of nasal polyps, hayfever, or other ear-nose-throat problems (such as deviated septum and epistaxis) and sinonasal cancer (table 3), and the association between the use of nasal preparations and sinonasal cancer persisted when respondents with a history of nasal polyps or ear-nose-throat problems were omitted from the analysis.

Prolonged or excessive use of topical decongestants can result in decreased vasoconstriction followed by increased rebound vasodilation. ${ }^{15}$ The resultant nasal congestant promotes continued use of the preparations. In our study, frequency and duration of use were closely associated: one-half of the cases who reported using nasal preparations for two or more years also reported that they used them for 26 or more weeks per year.

The possibility that the observed association between nasal preparation use and an increased risk of sinonasal cancer might be due to undetected confounding cannot be ruled out. Nonetheless, certain aspects of the relationship suggest that the association may be of aetiologic importance: (1) The association was not confounded by a history of nasal polyps, hayfever, ear-nose-throat problems, exposure to wood dust, smoking, alcohol use, age, or sex; and (2) A dose response relationship was observed both for weeks per year and number of years of nasal preparation use; increasing exposure was related to an increasing relative risk of sinonasal cancer.

The occurrence of sinonasal tumours has been related to direct inhalation of known or suspected carcinogens such as nickel, wood dust, and aromatic hydrocarbons. ${ }^{1617}$ Delayed mucociliary transport may also permit carcinogens to remain in contact with the sinonasal epithelium for an extended period of time, thus increasing the likelihood of malignant transformation. ${ }^{16}$ Several reports have suggested that preparations containing sympathomimetic amines may result in loss of cilia, fibrosis, and degeneration of nerve tissue. ${ }^{318-21}$ The use of preparations containing corticosteroids has also been associated with perforation of the nasal septum and increased irritation and dryness of the nasal mucosa. ${ }^{12}$ These observations are consistent with the hypothesis that the long-term use of nasal preparations might create an environment more favourable for carcinogenesis through a local reduction of mucociliary transport and the induction of necrotic changes in the sinonasal epithelium.

The finding of an apparent increase in the risk of sinonasal cancer associated with the use of topical nasal preparations suggests that the potential hazards associated with the use of these preparations should be investigated in greater detail. Given that a potential association between nasal preparation use and sinonasal cancer was not the main hypothesis of this study, the inability to verify nasal preparation exposure and the potential for inaccurate recall among subjects interviewed several years after diagnosis suggest the need for cautious interpretation of the results. Future research providing a more detailed examination of nasal preparation use may provide an insight into a potential risk factor for sinonasal cancer.

This work was supported in part by the United States Environmental Protection Agency through Contract No. 68-01-6280 to the Office of Toxic Substances.

The views expressed in this paper are those of the authors and do not necessarily reflect the views or the policies of the United States Environmental Protection Agency. 
Correspondence to Clifton H Strader, $\mathrm{PhD}$, Hanford Environmental Health Foundation, Post Office Box 100, Richland, Washington 99352. Reprint requests to Thomas L Vaughan, MD, Division of Public Health Services, Fred Hutchinson Cancer Research Center, 1124 Columbia Street (W-404), Seattle, Washington 98104.

\section{References}

${ }^{1}$ Miller F. Occurrence of nasal septal perforation with use of intranasal dexamethasone aerosol. Ann Allergy 1975; 34: 107-9.

2 Schoelzel EP, Menzel ML. Nasal sprays and perforation of the nasal septum. JAMA 1985; 253: 2046.

${ }^{3}$ Toohill RJ, Lehman RH, Grossman TW, Belson TP. Rhinitis medicamentosa. Laryngoscope 1981; 91: 1614 21.

${ }^{4}$ Hayes RB, Raatgever JW, De Bruyn AE. Tumours of the nose and nasal sinuses: a case-control study. Technical Report. Rotterdam: Department of Public Health and Social Medicine, Erasmus University, 1984; 19-22.

5 Vaughan TL, Strader C, Davis S, Daling JR. Formaldehyde and cancers of the pharynx, sinus and nasal cavity: I. occupational exposures. Int J Cancer 1986; 38: 677-83.

${ }^{6}$ World Health Organisation. ICD-O International classification of diseases for oncology. Geneva: World Health Organisation, 1976.

${ }^{7}$ Waksberg J. Sampling methods for random digit dialing. $J$ Am Statistical Assoc 1978; 73: 40-6.

${ }^{8}$ Mantel N, Haenszel W. Statistical aspects of the analysis of data from retrospective studies of disease. $J$ Natl Cancer Inst 1959; 22: 719-48.

${ }^{9}$ Cornfield J. A statistical problem arising from retrospective studies. Proceedings of the Third Berkeley Symposium. Berkeley: University of California Press, $1956 ; 135-48$.
${ }^{10}$ Gart J. The comparison of proportions: a review of significance tests, confidence intervals and adjustments for stratification. Rev Int Statistical Inst 1971; 39: 148-69.

11 Breslow NE, Day NE. Statistical methods in cancer research. Vol 1. The analysis of case-control studies. Lyon, France: International Agency for Research in Cancer, Publication 32, 1980; 122-61.

12 Brinton LA, Blot WJ, Becker JA, Winn DM, Browder JP, Farmer JC, Fraumeni Jr JF. A case-control study of cancers of the nasal cavity and paranasal sinuses. Am J Epidemiol 1984; 119: 896-906.

${ }^{13}$ Hayes RB, Raatgever JW, De Bruyn AE, Gerin M. Cancer of the nasal cavity and paranasal sinuses, and formaldehyde exposure. Int $J$ Cancer 1986; 37: 487-92.

${ }^{14}$ Elwood JM. Wood exposure and smoking: association with cancer of the nasal cavity and paranasal sinuses in British Columbia. Can Med Assoc J 1981; 124: 1573-7.

15 Rutka J, Alberti PW. Toxic and drug-induced disorders in otolaryngology. Otolaryngologic Clin North Am 1984; 17 : 761-74.

${ }^{16}$ Redmond CK, Sass RE, Roush GC. Nasal cavity and nasal sinuses. In: Schottenfeld D, Fraumeni JR, eds. Cancer epidemiology and prevention. Philadelphia: W. B. Saunders, 1982; 519-35.

17 Tola S, Hernberg S, Collan Y, Linnborg H, Korkala M. A case-control study of the etiology of nasal cancer in Finland. Int Arch Occup Environ Health 1980; 46: 79-85.

${ }^{18}$ Fox N. The chronic effect of epinephrine and ephedrine on the nasal mueosa. Arch Otol 1931; 13: 73-76.

${ }^{19}$ Ryan R. Vasomotor rhinitis medicamentosa viewed histologically. Staff Mayo Clin 1947; 22: 113-7.

${ }^{20}$ Mygind N, Thomsen J, Jorgensen MB. Ultrastructure of the epithelium of atrophic rhinitis. Acta Otolaryng 1974; 77: $439-46$.

${ }^{21}$ Cauna N, Cauna D. Association of nerve fibers and plasma cells in abnormal human nasal respiratory mucosa. Ann Otol 1974; 83: 347-59.

Accepted for publication May 1988 